\title{
Branching pattern of the femoral artery at the femoral triangle: a cadaver study
}

\author{
MB Samarawickrama ${ }^{1}$, BG Nanayakkara ${ }^{2}$, KWR Wimalagunarathna ${ }^{3}$, DG Nishantha ${ }^{3}$, UB Walawage ${ }^{3}$ \\ ${ }^{1}$ Lecturer, ${ }^{2}$ Professor, ${ }^{3}$ Demonstrator, Department of Anatomy, Faculty of Medicine, University of Ruhuna, Galle. \\ e-mail address of the corresponding author,Dr.M.B.Samarawikcrama: samaramb@gmail.com
}

\begin{abstract}
Introduction: The proper knowledge of the course and ramification of the blood vessels of the lower limbs is very important for surgeons and interventional radiologist. This is because the lower limb arteries are commonly involve with peripheral occlusive arterial diseases and the femoral artery at the femoral triangle is widely used for certain clinical procedures like arterial catheterization. Although there are several studies on the branching pattern of the femoral artery in the femoral triangle the Sri Lankan studies are spars.

Methodology and Materials: The branching pattern of the common femoral artery in the femoral triangle was studied during the educational dissection of human cadavers in the department of anatomy faculty of medicine Karapitiya. We used 26 femoral triangles in 13 cadavers. The pattern of origin of the profunda femoris artery and circumflex femoral arteries were studied.

Results: The level of origin of the profunda femoris was varying from 30 to $70 \mathrm{~mm}$ from the mid point of the inguinal ligament. Most of the time, the profunda artery on the left side tends to originate from a point proximal to the origin of the right profunda femoris artery. The lateral circumflex artery originated commonly from the femoral artery while the commonest site of origin of the medial circumflex arterial was the profunda artery. All these three arteries originated from a common trunk from the femoral artery in 2 out of 26 instances.

Conclusion: The profunda femoris was originated commonly from the posterior surface of the common femoral artery. However, we encountered six out of 26 arteries starting from the lateral aspect of the femoral artery and this was not mention in text. The average distance of the origin of the profunda was $50 \mathrm{~mm}$ from the mid point of the inguinal ligament. This is a slightly higher distance than reported in the literature. Twenty four out of 26 lateral circumflex arteries were started from the profunda femoris artery while the other two started from a common trunk from the femoral artery. We did not encounter instances where lateral circumflex arteries originated from the common femoral artery. However, $31 \%$ of medial circumflex femoral arteries originated from the common femoral artery even though in most of the instances the circumflex arteries originated from the profunda femoris artery which is comparable to the reports in the literature.
\end{abstract}

\section{Introduction:}

The course and ramification of the vessels of the lower limbs have long received attention from anatomists and surgeons. The profunda femoris artery usually arises from the posterolateral aspect of the femoral artery. The medial and lateral circumflex femoral arteries normally arise from the profunda femoris artery near its origin ${ }^{1}$. The femoral artery is commonly used for arterial catheterization as it can be readily accessed. Thereby it is used for investigation of any arterial system in the body and for various clinical procedures like coronary angioplasty. In addition to those the femoral artery at the femoral triangle is directly opened at the origin of the profunda femoris artery ${ }^{2}$ for femoral embolectomy in lower limb arterial thrombo embolism. In all these cases the anatomical knowledge of the profunda femoris artery and the circumflex arteries is very important to prevent inadvertent damage to these during clinical procedures. Several case reports on the branching 
pattern and variations of the femoral and profunda femoris arteries have been reported. However the data on anatomy of these arteries in the femoral triangle in Sri Lankan is sparse. Therefore the aim of the study was to identify the pattern of ramification of these arteries in our region.

\section{Materials and Method:}

Dissections of 26 femoral triangles in 13 human cadavers during the educational dissection with undergraduate students of the Department of Anatomy of the faculty of medicine Karapitiya were used for the study. The femoral artery and the profunda femoris artery with its medial and lateral circumflex femoral branches were dissected and their origins were identified. The relation of the profunda femoris at its origin to the femoral artery was studied. The distance of the site of origin of the profunda was measured from the mid point between the anterior superior iliac spine and the pubic tubercle in millimeters with a scale. The sites of origin of the medial and lateral circumflex femoral arteries were also studied and the distance of site of origin of each of them were measured from the origin of profunda femoris artery in millimeters.

\section{Results:}

The profunda femoris artery originated from either posterior $(12 / 26)$, posterolateral $(8 / 26)$ or lateral $(6 / 26)$ aspect of the common femoral artery.

The distance of origin of profunda femoris from the midpoint of the inguinal ligament on the right side commonly placed between 51 and $70 \mathrm{~mm}$ whereas on the left side it was between 21 and 50mm (Table 1).

Table 1 - Distance of origin of profunda femoris from the midpoint of the inguinal ligament .

\begin{tabular}{|l|c|c|}
\hline Range (mm) & $\begin{array}{c}\text { No. on right } \\
\text { side }\end{array}$ & $\begin{array}{c}\text { No. on left } \\
\text { side }\end{array}$ \\
\hline $21-30$ & 1 & 3 \\
\hline $31-40$ & 1 & 3 \\
\hline $41-50$ & 3 & 3 \\
\hline $51-60$ & 4 & 2 \\
\hline $61-70$ & 4 & 2 \\
\hline
\end{tabular}

The position of the origin of the profunda artery was from the posterior, posterolateral or lateral side of the common femoral artery (Table 2). When the profunda artery was originated more proximally it was originated from the lateral side of the common femoral artery (Figure 1).

Table 2 - The position of the origin (Posterior, Posterolateral or Lateral) of the artery verses the distance of the origin of profunda artery from the common femoral artery.

\begin{tabular}{|l|l|l|c|}
\hline Range (mm) & Posterior & Posterolateral & Lateral \\
\hline $21-30$ & 0 & 0 & 4 \\
\hline $31-40$ & 2 & 0 & 2 \\
\hline $41-50$ & 2 & 4 & 0 \\
\hline $51-60$ & 5 & 2 & 0 \\
\hline
\end{tabular}

The origin of the lateral circumflex femoral artery on the right side was from the profunda femoris artery in 12 out of 13 cases $(92 \%)$. It was from the profunda femoris common stem in 1 case $(8 \%)$. None was originated from the femoral artery. Exactly similar figures were observed in the left side as well. However the left side common stem was seen in a different subject.

Most of the time the distance of origin of the lateral circumflex femoral artery from the origin of the profunda was between 01 and $40 \mathrm{~mm}$. (Table 3). Interestingly 11 out of 12 on the right side and 08 out of 12 on the left side were originated between 01 and $30 \mathrm{~mm}$ from the origin of the profunda femoris.

Table 3 - Distance of the origin of lateral circumflex femoral artery from the profunda femoris artery (measured from the origin of the profunda femoris).

\begin{tabular}{|l|c|c|}
\hline Range (mm) & $\begin{array}{c}\text { No. on right } \\
\text { side }\end{array}$ & $\begin{array}{c}\text { No. on left } \\
\text { side }\end{array}$ \\
\hline $01-10$ & 3 & 2 \\
\hline $11-20$ & 3 & 2 \\
\hline $21-30$ & 5 & 4 \\
\hline $31-40$ & 1 & 1 \\
\hline $41-50$ & 0 & 2 \\
\hline $51-60$ & 0 & 1 \\
\hline
\end{tabular}

On the right side the medial circumflex femoral artery arose from the profunda in 8 out of 13 cases (62\%), from the femoral in 4 out of 13 cases $(31 \%)$ 
and from the profunda femoris common stem in one case $(8 \%)$. A similar pattern was observed in the left side as well having similar number of medial circumflex arteries originated from the profunda femoris and the femoral artery. Similarly one medial circumflex artery originated from the common profunda femoris stump (Figure 2). When the artery was originated from the femoral artery it was above the origin of the profunda femoris (Figure 3) in all the cases and it was within $5 \mathrm{~mm}$ to $30 \mathrm{~mm}$ above the origin of the profunda femoris artery (Table 4).

Table 4 - Distance of origin of the medial circumflex femoral artery from the common femoral artery (measured from the origin of the profunda femoris).

\begin{tabular}{|c|c|c|}
\hline Range (m m) & $\begin{array}{c}\text { No. on } \\
\text { right side }\end{array}$ & $\begin{array}{c}\text { No. on } \\
\text { left side }\end{array}$ \\
\hline $01-10$ & 2 & 4 \\
\hline $11-20$ & 0 & 0 \\
\hline $21-30$ & 2 & 0 \\
\hline
\end{tabular}

The distance of origin of the medial circumflex femoral from profunda artery was between 01 and $30 \mathrm{~mm}$ on the right while on the left it was between 11 and $40 \mathrm{~mm}$ (Table 5).

Table 5 - Distance of origin of medial circumflex femoral artery from the profunda femoris (measured from the origin of the profunda femoris artery).

\begin{tabular}{|l|c|c|}
\hline Range (mm) & $\begin{array}{l}\text { No. of cases } \\
\text { on right side }\end{array}$ & $\begin{array}{l}\text { No. of cases } \\
\text { on left side }\end{array}$ \\
\hline $01-10$ & 3 & 0 \\
\hline $11-20$ & 2 & 4 \\
\hline $21-30$ & 3 & 2 \\
\hline $31-40$ & 0 & 2 \\
\hline
\end{tabular}

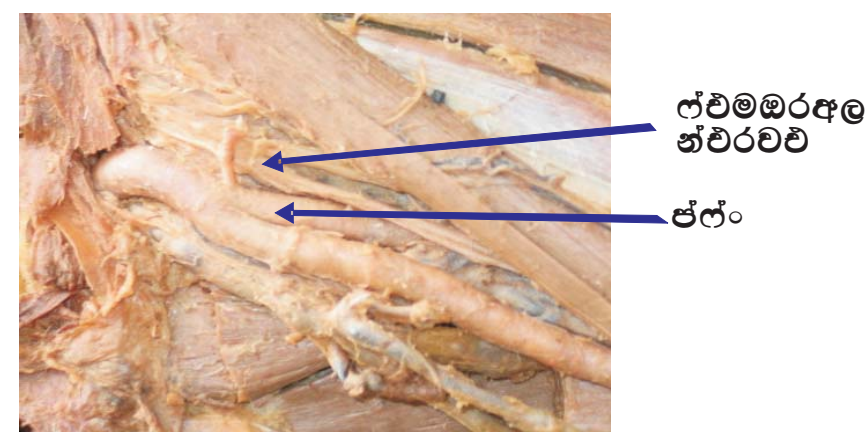

Figure 1 - Profunda femoris originating from the lateral aspect of the common femoral artery.

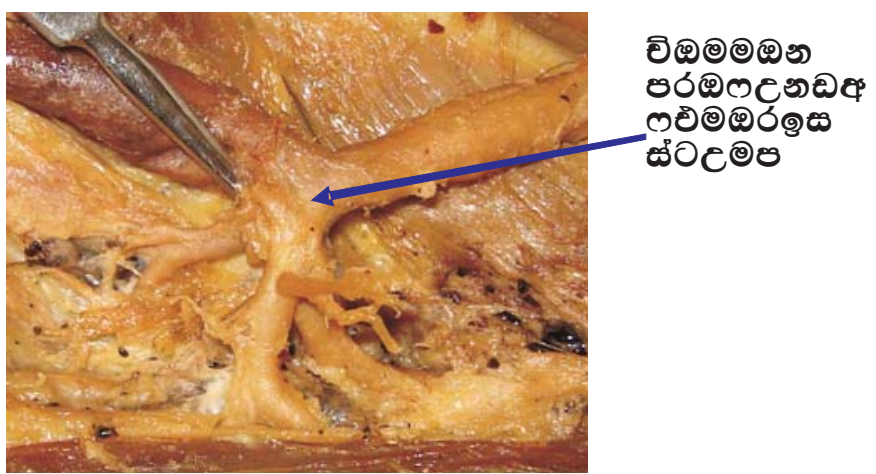

Fig 2 - Femoral artery giving the three arteries from a common stem.

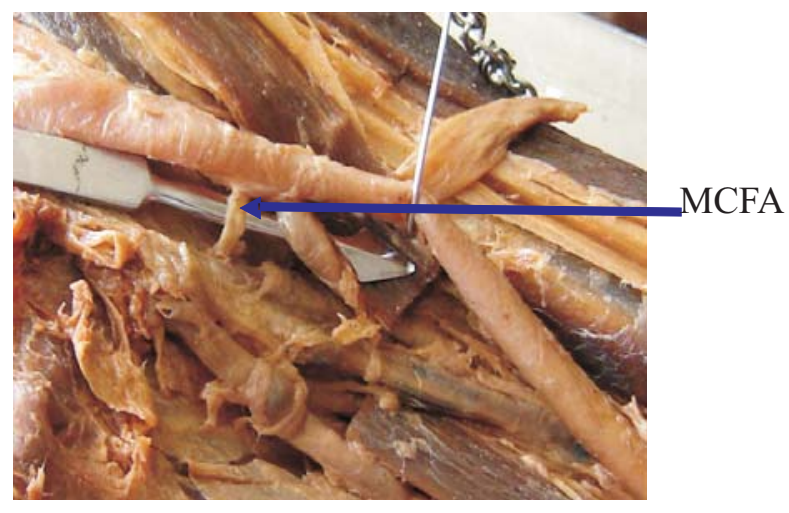

Figure 3 - Medial circumflex femoral artery originating from the common femoral artery.

\section{Discussion}

The profunda femoris artery in our study originated mostly from the posterior side of the common femoral artery $(12 / 26,46 \%)$. Thirty percent of the time $(8 / 26)$ it originated from the posterolateral side of the femoral artery. These two sides of origin have been described in the anatomy texts as the sides of the origin of the artery ${ }^{1}$. However, we encountered 6 out of 26 arteries $(23 \%)$ originated from the lateral aspect of the common femoral artery (Figure 1). When comparing the side of origin and the distance of origin of the profunda artery an interesting feature was noted (Table 2). It showed that when the artery is originated close to the inguinal ligament (shorter the distance of origin) it arises from the lateral side of the common femoral artery.

The average distance of origin of profunda femoris from the midpoint of inguinal ligament on the right side was $55 \mathrm{~mm}$ and on the left side was $45 \mathrm{~mm}$. This indicates that the origin of the left profunda artery is usually proximal to the origin of the right profunda 
artery. The average distance of origin was $50 \mathrm{~mm}$ when both sides taken together. This distance was more than the average distance of origin reported in the literature by Dixit, et $\mathrm{al}^{3}(47.5 \mathrm{~mm})$, Bannister et $\mathrm{al}^{4}(35 \mathrm{~mm})$ and Siddharth ${ }^{5}$ et al $(44 \mathrm{~mm})$. The knowledge of the site of origin of the profunda helps in avoiding iatrogenic femoral arterio-venous fistula while performing femoral artery puncture and it enable to identify the correct site of making incision for surgical exposure of the common femoral and profunda femoris junction.

The lateral circumflex femoral artery mostly originated from the profunda femoris artery in 24 out of 26 arteries dissected $(92.3 \%)$. This is the commonest pattern of origin of this artery sited in the literature ${ }^{3,6,7}$. The figure was $77.3 \%$ in Turkish population ${ }^{7}$ where as in our study it was $92 \%$. The rest $8 \%$ of cases originated from a common trunk for the profunda and circumflex arteries. We did not encounter any originated from the common femoral artery.

The medial circumflex artery on an average arose in $62 \%$ of cases from the profunda femoris artery which was similar to the finding in an Indian study ${ }^{3}$. The proportion originated from the common femoral artery was $31 \%$. This is comparable to some other studies where most of the time the medial circumflex femoral artery originated from the profunda femoris artery ${ }^{8}$. The distance of the origins of both circumflex arteries from the profunda commonly falls within 01 to $30 \mathrm{~mm}$ from the origin of the profunda artery. Thus the origin of circumflex arteries placed very close to the root of the profunda artery. This is comparable to the classical text book description ${ }^{1}$.

In conclusion, the origin of the profunda femoris artery in our study is placed more distally than the other studies. However, the left profunda femoris originates more proximally than the right profunda origin in most of the cases. We encountered that in $23 \%$ of cases the profunda is originated from the lateral aspect of the common femoral artery. Interestingly the profunda started laterally when it originates closer to the inguinal ligament. The lateral circumflex femoral artery and medial circumflex femoral artery commonly originate from the profunda femoris artery close to the origin of the profunda femoris artery. This knowledge is very valuable in preventing iatrogenic injury to these vessels during surgical procedures of the femoral triangle. Further study is necessary to identify gender differences to these arteries.

\section{References}

1. GJ Romanes. Upper and Lower limbs. Cunningham's Manual of Practical Anatomy. Vol 1, $15^{\text {th }}$ ed. Oxford University Press, 1987; pp 141.

2. RM Kirk. General Surgical Operations. $4^{\text {th }}$ ed. In Churchill Livingston, 2000; p542.

3. DP Dixit, LA Mehta, ML Kothari. Variations in the Origin and Course of Profunda Femoris. Journal of the Anatomical Society of India 2001; 50(1): 6-7.

4. LH Bannister, MM Berry, P Collins, Gray's Anatomy. In: Cardiovascular system. $38^{\text {th }}$ Edition; Churchill Livingstone, Medical Division of Longman Group, UK Ltd. 1995. pp 1566-8.

5. P Siddharth, NL Smith, RA Mason, F Giron. Variational anatomy of the deep femoral artery. PMID: 3842043 [PubMed - indexed for MEDLINE].

6. MT Vazquez, J Murillo, E Maranillo, I Parkin, J Sanudo. Patterns of the circumflex femoral arteries revisited. PMID: 16617441 [PubMed - indexed for MEDLINE].

7. M Uzel, E Tanveli, M Yildirim. An anatomical study of the origins of lateral circumflex femoral artery in the Turkish population. PMID: 19085859 [PubMed - indexed for MEDLINE].

8. E Tanyeli, M Uzel, M Yildirim, HH Celik. An anatomical study of the origins of the medial circumflex femoral artery in the Turkish population. PMID: 12557421 [PubMed - indexed for MEDLINE]. 